\title{
Reinvençáo guiada e o ensino de Matemática: um estudo das representaçóes semióticas que emergem de uma atividade
}

\author{
Marcele Tavares Mendes* \\ Karina Alessandra Pessoa da Silva**
}

\begin{abstract}
Resumo
Neste artigo apresentamos resultados de uma pesquisa na qual investigamos as representaçóes semióticas para os objetos matemáticos em uma atividade desenvolvida segundo a estratégia de ensino da reinvenção guiada. A pesquisa está fundamentada nos pressupostos teóricos da Teoria dos Registros de Representação Semiótica de Raymond Duval e nos princípios da abordagem de ensino da Educação Matemática Realística. As nossas reflexões são subsidiadas pela análise da produção escrita de professores em formação em um curso de curta duração. Por meio das representaçóes que emergiram de uma atividade desenvolvida no âmbito do curso, pudemos inferir que o contato com diferentes representaçóes semióticas possibilita sua complementação e a compreensão dos objetos matemáticos.
\end{abstract}

Palavras-chave: Educação Matemática Realística, registros de representação semiótica, reinvenção guiada.

\section{Guided Reinvention and teaching of Mathematics: a study of semiotic representations emerging from an activity}

\begin{abstract}
In this article we present results of a research in which we investigate the semiotic representations for the mathematical objects in an activity developed according to the Guided Reinvention teaching strategy. The research is based on the theoretical assumptions of Raymond Duval's Theory of Registers of Semiotic Representation and the principles of the teaching approach Realistic Mathematical Education. Our reflections are subsidized by the analysis of the written production of teachers in training in a short course. Through the representations that emerged from an activity developed within the scope of the course, we could infer that the contact with
\end{abstract}

* Docente da Universidade Tecnológica Federal do Paraná (UTFPR), Londrina/PR. Licenciatura e bacharelado em Matemática pela Universidade Estadual de Londrina, Mestrado em Matemática pela Universidade Estadual de Maringá, Doutorado em Ensino de Ciências e Educação Matemática pela Universidade Estadual de Londrina, Docente do Programa de Mestrado Profissional em Ensino de Matemática da UTFPR - Londrina/Cornélio Procópio. E-mail: marceletavares@utfpr.edu.br.

** Docente da Universidade Tecnológica Federal do Paraná (UTFPR), Londrina/PR. Licenciatura em Matemática pela Universidade Estadual de Londrina, Mestrado e Doutorado em Ensino de Ciências e Educaçâo Matemática pela Universidade Estadual de Londrina, Docente do Programa de Mestrado Profissional em Ensino de Matemática da UTFPR - Londrina/Cornélio Procópio. E-mail: karinapessoa@gmail.com. 
different semiotic representations allow its complementation and the understanding of the mathematical objects.

Keywords: Realistic Mathematics Education, registers of semiotic representation, guided reinvention.

\section{Introdução}

A pesquisa sobre práticas efetivas para o ensino de Matemática tem sido temática recorrente na área de Educação Matemática. Muitos trabalhos versam sobre possibilidades de implementar atividades com potencial para estimular diferentes representaçóes de modo que o acesso aos objetos matemáticos seja facilitado.

Isso ocorre, porque toda comunicação em Matemática é feita por meio de representaçóes. O que se estuda e se ensina são as representaçóes dos objetos matemáticos e não os próprios objetos matemáticos. D’Amore, Pinilla e Iori (2015, p. 131) afirmam que o "que podemos fazer com os objetos matemáticos é descrevê-los, defini-los, denotá-los, denominá-los, desenhá-los”, pois os objetos matemáticos não podem ser indicados, nem mostrados.

Ao pensar em um modo de como estudar e como ensinar essas representaçôes dos objetos matemáticos, apresentamos aspectos da reinvenção guiada, estratégia de ensino da Educação Matemática Realística, em que em vez de o professor apresentar as ferramentas e os conceitos matemáticos prontos e acabados, o que Freudenthal (1971) chamou de inversão antididática, dá-se a oportunidade aos estudantes de "reinventá-los", de acordo com suas necessidades e nível de compreensão, atribuindo-lhes o papel de protagonistas no processo de aprendizagem e, com isso, também responsáveis por ele.

Nesse contexto, temos como objetivo investigar que representaçóes emergem da realizaçáo de uma atividade desenvolvida na perspectiva da reinvençáo guiada e como essas representaçóes podem se complementar para que ocorra a aprendizagem em matemática.

Com isso, neste artigo subsidiamos as nossas reflexóes na análise do desenvolvimento de uma atividade proposta em um curso de curta duração para professores que ensinam matemática, pois são esses os atores do ensino na escola. Para tanto, apresentamos uma discussão dos resultados e inferências realizadas acerca da questão de investigação, tomando como ponto de partida os aspectos teóricos das representaçóes semióticas e da reinvenção guiada. 


\section{Sobre representaçóes semióticas}

Representar surge da necessidade de tornar algo presente; algo que exista e que necessite da representação para ser acessado. Ao se pensar o ensino de Matemática, é desejável favorecer ao aluno a oportunidade de desenvolver diferentes representaçóes para um mesmo objeto matemático, reconhecendo sua possível utilização em situações diversas. Duval (2004) afirma que não há um conhecimento que uma pessoa possa mobilizar sem uma atividade de representação. Segundo esse autor, as representações semióticas são produçôes constituídas pelo emprego de signos pertencentes a um sistema de representação, os quais têm suas dificuldades próprias de significado e de funcionamento.

A complexidade dos fatores relacionados às formas de representação no processo de ensino e aprendizagem tem sido o foco de diversas pesquisas em Educação Matemática. Font, Godino e D’Amore (2005) afirmam que a principal razão seria o fato de que falar de representação equivale a falar de conhecimento, significado, compreensão etc.

No entanto, como afirma Otte (2001), apesar de um objeto matemático não existir independentemente $\mathrm{da}$ totalidade de suas possíveis representaçóes, esse objeto não deve ser confundido com alguma representação particular. Duval (2004) também trabalha com essa consideração, afirmando que "[...] não há compreensão em Matemática se não se distingue um objeto de sua representação" (p. 14). O autor afirma que existem sempre muitas representaçóes possíveis para um mesmo objeto, mas nenhuma é suficiente para expressar toda a característica do objeto. As representaçóes do objeto apresentam um caráter de variabilidade, pois mudam de acordo com os pontos de vista considerados e os sistemas físicos ou semióticos utilizados para produzir a representaçáo. $\mathrm{O}$ objeto, no entanto, apresenta uma característica de invariância com relação à variabilidade possível de suas representaçôes.

D’Amore, Pinilla e Iori (2015, p. 112), afirmam que "cada representação semiótica veicula somente alguns dos aspectos conceituais que são componentes do objeto considerado".

Em seus estudos sobre representaçóes semióticas, Duval (2003, p. 14), utiliza a expressão "registros de representação semiótica". Pautados em estudos da teoria dos registros de representação semiótica, Henriques e Almouloud (2016, p. 469) afirmam que "o registro é o sistema no qual 
ocorre ou se realiza a representação de um dado objeto, externando, assim, o objeto não ostensivo (ideia, noção, conceito) pensado pelo sujeito".

Segundo Duval (2003), um sistema semiótico é considerado um registro de representação se atende a três atividades cognitivas fundamentais: a formação de uma representação identificável, o tratamento e a conversão.

Para que uma representação seja identificável, é necessário, a partir de um registro de representação, saber qual é o objeto matemático que está sendo representado. $\mathrm{O}$ tratamento ocorre quando há transformaçóes de representaçóes dentro de um mesmo sistema de registros. A conversão corresponde a transformaçóes de representaçóes onde há mudanças de sistemas de registros, conservando o objeto matemático estudado.

É importante transitar entre os diferentes tipos de representaçáo, fazendo a conversão de representação de um registro para outro. Para Duval (2003, p. 16), “[...]do ponto de vista cognitivo, é a atividade de conversáo que, ao contrário, aparece como a atividade de transformaçáo representacional fundamental, aquela que conduz aos mecanismos subjacentes à compreensão".

Além da realização da conversão de uma representação de um registro para outro, Duval (2004) considera que a conceitualização do objeto matemático em estudo ocorre quando há uma coordenação entre os registros, ou seja, quando há a compreensão de que os diferentes registros se referem ao mesmo objeto matemático e podem se complementar, no sentido de que um registro pode expressar características ou propriedades do objeto matemático que não são expressas com clareza em outro registro.

Na prática de sala de aula, todavia, corroboramos com Henriques e Almouloud (2016) quando afirmam que:

A representação de um objeto e a conversão de representaçóes entre registros, por exemplo, são comuns nas práticas do professor de Matemática em sala de aula, quando este pretende fazer com que os seus alunos compreendam uma determinada noção de difícil entendimento no registro no qual o objeto foi inicialmente apresentado. No momento em que o professor realiza essa conversáo, não implica, necessariamente que ele queira reforçar a estreita relaçáo existente entre os registros que mobilizou. (HENRIQUES; ALMOUOUD, 2016, p. 467).

Mesmo que o professor não tenha a intenção de estabelecer relaçôes entre representaçóes semióticas pertencentes a diferentes sistemas, quando 
realiza uma conversão, possibilita a seus alunos transitar entre diferentes registros, de modo que as diferentes representaçôes possam se complementar e, consequentemente, ocorra aprendizagem.

Diferentes representaçóes pertencentes a diferentes sistemas semióticos podem se fazer presentes na estratégia de ensino adotada pelo professor. Nesta pesquisa optamos pela reinvenção guiada.

\section{Sobre reinvenção guiada}

A reinvenção guiada é tomada como a estratégia (método) de ensino da abordagem Educação Matemática Realística. Nessa abordagem, os conceitos matemáticos, as estruturas e as ideias são considerados ferramentas para organizar fenômenos do mundo físico, social e mental, uma vez que resultaram da resolução de problemas (FREUDENTHAL, 1979).

Essa abordagem de ensino pode ser caracterizada por seis princípios, esses princípios são discutidos por Van den Heuvel-Panhuizen (2010). Resumidamente, o "princípio da atividade" abarca a interpretação da matemática como atividade humana, na qual os alunos são participantes ativos de seus processos de aprendizagem. O "princípio da realidade" refere-se à necessidade de todo o processo de aprendizagem ser marcado por tarefas que contemplem contextos ricos e que necessitem de organização. $\mathrm{O}$ "princípio de nível" ressalta a individualidade e os diferentes níveis de compreensão na aprendizagem da matemática. O "princípio do entrelaçamento" sublinha a ideia de que os domínios da matemática sejam tratados de maneira fortemente integrada, de tal modo que as tarefas propostas aos alunos demandem a utilizaçáo de vários conhecimentos e ferramentas matemáticas. O "princípio da interatividade" apresenta a ideia de a aprendizagem da matemática ser uma atividade social, sendo necessário dar aos alunos a oportunidade de compartilhar suas estratégias, invençôes e descobertas. Por fim, o "princípio da orientação" diz respeito ao papel de "guia" que os professores assumem em todo o processo, assim como a função dos programas educacionais de disponibilizar cenários com potencial para fomentar o processo de aprendizagem de cada estudante.

Esses princípios comportam-se como pressupostos para um professor organizar sua prática pedagógica. É desejável que o professor elabore um possível planejamento do ambiente de ensino e aprendizagem que poderá se constituir na prática ou retomado a partir das produçóes emergentes num 
contexto de sala de aula. Nesse planejamento, uma trajetória de ensino e de aprendizagem, o professor pode prever e retratar as principais açôes e atividades, deixar claro como as competências serão desenvolvidas em conexão com outras. Nessa trajetória, diferentes representaçóes para um mesmo objeto podem ser realçadas, evidenciando caminhos que lidam com suas dificuldades e funcionamentos próprios.

Conforme Van den Heuvel-Panhuizen (2000), sem manter essa trajetória não é possível orientar a aprendizagem dos alunos. $\mathrm{Na}$ perspectiva da Educação Matemática Realística, essa trajetória deve expressar possíveis encaminhamentos que favoreceram ao aluno vivenciar um processo de invenção da Matemática por eles próprios, guiados pelos professores. Guiado pelo professor no sentido de orientá-los e acompanhá-los, a partir de suas produçóes, para que possam inventar/construir/lidar com ferramentas matemáticas em diferentes atividades. Esse guiado faz parte da estratégia de ensino denominada reinvenção guiada.

O foco principal da reinvenção guiada não está em uma matemática pronta e acabada e, sim, na atividade, no realizar. Santos (2014, p. 40) apresenta alguns aspectos da dinâmica da aula sob a perspectiva da reinvenção guiada, sendo eles:

- O trabalho em sala de aula tem início com a proposição de uma situação realística que possibilita diferentes níveis de matematização.

- Após resolverem a situação, os alunos podem interagir uns com os outros e terem a oportunidade de analisar e discutir estratégias e procedimentos que utilizaram.

- Durante e após o trabalho dos alunos, o professor pode fazer questionamentos para explorar as resoluçôes que apresentaram bem como as diferenças existentes entre elas, e discutir aspectos matemáticos subjacente a essas resoluçóes encorajando-os a se interessar por esses aspectos.

O trabalho do professor se torna indispensável e de fundamental importância já que é ele quem prepara o caminho (as aulas) a ser percorrido pelos estudantes durante o reinventar a matemática. Esse caminho pode ser direcionado por meio das atividades (situaçóes realísticas, aquelas que os alunos podem imaginar) escolhidas, elaboradas ou desenvolvidas pelos professores. 
Segundo Van den Heuvel-Panhuizen (1996), as atividades escolhidas pelos professores devem permitir que o processo de aprendizagem seja transparente para os professores e para os estudantes; oportunizar ir de competências básicas para o pensamento de ordem superior; ser familiares aos estudantes; oferecer oportunidades para matematizar; ser resolvíveis de formas diferentes em diferentes níveis.

À luz desses pressupostos, interessa-nos discutir possibilidades para a sala de aula com base no uso de diferentes representaçóes planejadas para uma atividade resolvida por professores (ou futuros professores) em um contexto de aula baseado na reinvençáo guiada. As possibilidades aqui discutidas vão na direção de apresentar coordenaçóes entre diferentes registros de representação e essas coordenaçóes poderem gerar reflexóes para o professor no momento de elaborar suas trajetórias de ensino e de aprendizagem.

\section{Procedimentos metodológicos}

A nossa discussão baseia-se no encaminhamento/resolução de uma atividade por professores de matemática em momento de formação em um curso de curta duração em um evento de Educação Matemática realizado no Paraná, no qual objetivou explorar diferentes representações a partir da estratégia de ensino reinvenção guiada e gerar reflexôes para o professor no momento de elaborar suas trajetórias de ensino e de aprendizagem. As autoras deste texto foram as formadoras do processo, foram as que guiaram o "desenrolar" das atividades do curso. Ao longo do texto serão usados os termos "formadoras" para as regentes do curso e "professores" para os inscritos no curso.

No planejamento das atividades foi levado em consideração que não se conhecia de antemão o perfil dos participantes, por isso, o estudo contemplou conhecimentos matemáticos abordados desde o ensino fundamental, dado que o público do evento compreendia estudantes de graduaçáo, professores da educação básica e professores de graduação e pós-graduação. As atividades foram classificadas por situações realísticas por abrangerem contextos que podem ser imaginados pelos envolvidos.

Durante o curso, os professores, divididos em sete grupos com 4 integrantes, realizaram três atividades matemáticas. Para este texto escolhemos produçóes escritas de três grupos - Grupo 1, Grupo 2 e Grupo 3 - para uma das atividades propostas. A escolha se deve às limitaçóes do texto, bem 
como ao detalhamento apresentado e às resoluçốes por meio de diferentes representaçóes.

Do ponto de vista metodológico, essa discussão é um recorte de uma pesquisa de natureza qualitativa e de análise interpretativa. Essa natureza, conforme Bardin (2016, p. 146), caracteriza-se pelo fato da "inferência sempre que é realizada - ser fundada na presença do índice (tema, palavra, personagem etc.!), e não sobre a frequência da sua aparição".

Ancoramo-nos na Educação Matemática Realística por se tratar de uma abordagem utilizada no desenvolvimento, aperfeiçoamento e estudo de materiais instrucionais em Matemática que sirvam para apoiar a aprendizagem dos estudantes (KEENE; HALL; DUCA, 2014; SWINYARD, 2011; WATSON; OHTANI, 2013). Em especial, para o desenvolvimento deste curso destacamos a reinvenção guiada e a utilização de pontos de partida realísticos (GRAVEMEIJER, 1999), o que significa que os problemas matemáticos estão situados dentro de contextos que são significativos para estudantes.

A análise da produção escrita foi o recurso utilizado para identificar e discutir a(s) estratégia(s) e o(s) procedimento(s) escolhido(s) pelos professores na resolução da atividade. Por meio dela, buscou-se reconhecer as diferentes representaçóes utilizadas por cada grupo que diminuem a distância do sujeito ao objeto matemático.

Segundo Smith, Hillen e Heffernan (2001), a análise da produção escrita dos estudantes pode ser utilizada pelos professores na direção de obter um entendimento dos modos como os estudantes estão pensando e representando a matemática. Esses autores assinalam que,

se os professores forem capazes de interpretar e entender os modos que os estudantes pensam e representam a matemática, eles podem utilizar estratégias de ensino sobre esses entendimentos, como também, ajudar os alunos a fazer conexóes entre suas representaçôes idiossincráticas e aquelas mais convencionais. (SMITH; HILLEN; HEFFERNAN, 2001, p. 65).

Nesse contexto, investigamos as representaçóes que emergem da realização de uma atividade desenvolvida na perspectiva da reinvenção guiada e como essas representaçóes podem se complementar para que ocorra a aprendizagem em matemática. 


\section{Possibilidades para a viabilidade de diferentes registros de representa- ção semiótica}

Os aspectos da configuração desse momento de formação em que professores se envolveram são relevantes de ser observados e analisados, pois em uma aula que se toma a reinvenção guiada como estratégia de ensino, professores e alunos não possuem um roteiro (script) a ser considerado $a$ priori, mas são atores e autores em conjunto de todo o desenrolar que se póe nesta sala de aula.

Assim que o curso iniciou, as formadoras se apresentaram e ressaltaram a importância de todos os participantes se envolverem e participarem das discussões, também expuseram que a forma de trabalho em grupo seria a adotada. $\mathrm{O}$ trabalho em grupo promove a interação entre os envolvidos. Cobb e Yackel (1996) enfatizam a importância dessas interações, argumentando que a aprendizagem ocorre ao se negociar significados e interpretaçóes em busca de formas consensuais ou compatíveis de entendimento por meio de interaçóes sociais.

Em seguida, as formadoras entregaram o enunciado da primeira atividade matemática aos professores em uma folha de sulfite, a escolhida para ser apresentada neste texto, cujo enunciado é apresentado no Quadro 1.

\section{Quadro 1 - Enunciado da atividade}

Quinze meninas saem de um grupo de meninos e meninas. No grupo restante ficam dois meninos para cada menina. Aí então, 45 meninos abandonam o grupo. Ficam então 5 meninas para cada menino. Qual o número de meninas no grupo inicial?

\section{Fonte: Arquivo das autoras.}

A instrução dada a cada grupo de professores foi que com base no enunciado da questão explorasse possíveis encaminhamentos/resoluções, de modo que todos os professores (em princípio em seus pequenos grupos) pudessem participar e contribuir com a discussão. Para Gravemeijer (2008), uma maneira de promover o processo de reinvenção guiada é a interação entre os estudantes para desenvolver diferentes resoluçóes/estratégias/procedimentos. Sendo que essas resoluçóes distintas tornam- se o fomento da discussão provocada/guiada pelo professor entre os estudantes, destacando as diferenças entre os conteúdos matemáticos subjacentes às resoluçóes. 
As formadoras, como sujeitas que guiavam o processo, observaram o desenrolar da ação dos professores e por meio de questionamentos abertos sobre o processo de construção de cada grupo, tiveram a função de verificar a convergência das produçóes dos professores para as normas comuns dentro da comunidade matemática. O professor nessa estratégia de ensino não é prescritivo, mas por meio de intervençóes, desenha caminhos de reinvenção para guiar os estudantes nas aulas para desenvolverem sua própria matemática (DRIJVERS, 2003).

Após as discussóes nos pequenos grupos, as formadoras solicitaram que cada grupo escolhesse uma produção para discutir com toda a sala. Nessa discussão, por meio da argumentação, todos tiveram a oportunidade de utilizar representaçóes semelhantes com base em diferentes produçóes, o que pode levar ao desenvolvimento de conceitos matemáticos e favorecer conversôes entre representaçóes de um registro a outro.

Na Figura 1 é apresentada a produção do Grupo 1. Ao lado do registro escrito recolhido pelas formadoras, há o modo que os professores responsáveis por essa produção registraram na lousa - figura recolhida a partir da fotografia da lousa.

Figura 1 - Produção escolhida pelo Grupo 1

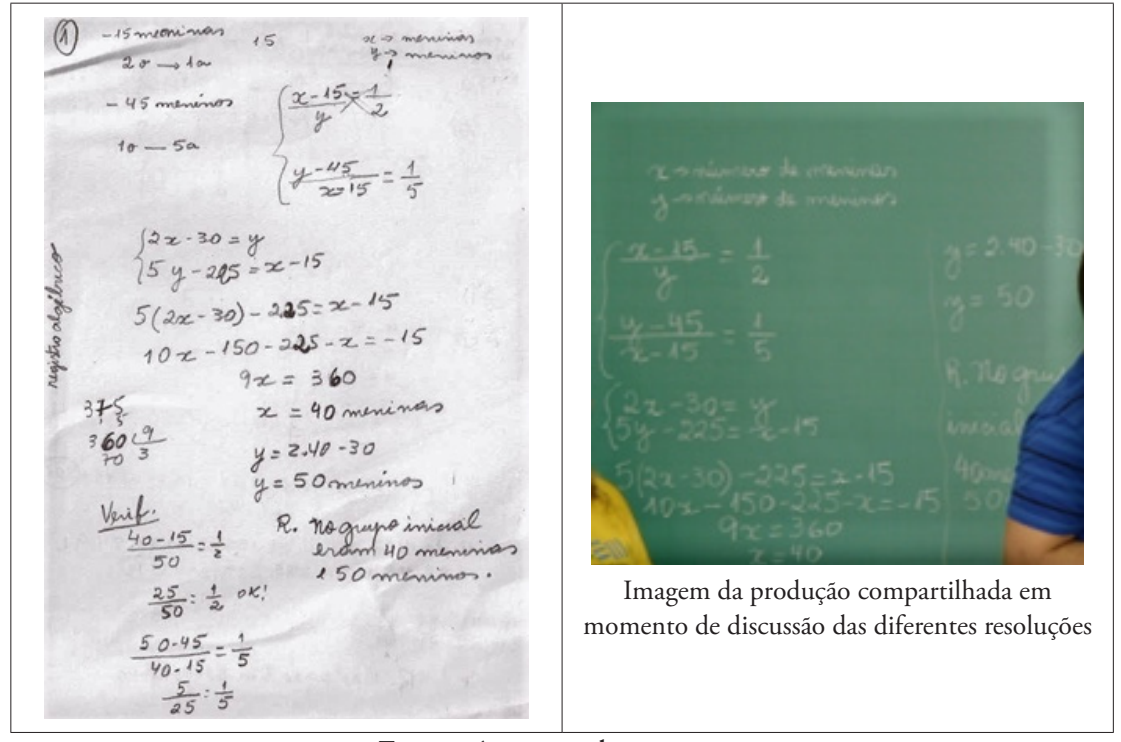

Fonte: Arquivo das autoras. 
Na produção apresentada pelo Grupo 1 é possível reconhecer que foi utilizada uma representação algébrica no momento em que é denotado $\mathrm{x}$ por meninas e y por meninos. Como estratégia de resolução foi utilizado o sistema de equações lineares e como procedimento de resolução, o método de substituição. É possível reconhecer que o princípio multiplicativo foi utilizado ao escrever dois sistemas equivalentes e que a propriedade distributiva da multiplicação foi utilizada após realizar a substituiçâo das incógnitas.

Para resolver a atividade, o Grupo 1 permanece no mesmo sistema semiótico, realizando tratamentos. Em Matemática, muitas vezes, o tratamento é a transformação que mais se evidencia nas atividades, pois o tratamento corresponde a procedimentos de justificação. Segundo Duval (2003), em atividades pedagógicas, professores tentam utilizar o "melhor" registro de representação para que os alunos possam "compreender" o que está sendo estudado, pois assim conseguem justificar uma ideia referente ao conteúdo.

$\mathrm{Na}$ Figura 2 é apresentada a produção do Grupo 2. Relacionada a esta apresentamos uma fotografia, no entanto, um membro do grupo argumentou que haviam elaborado uma solução com base na mesma estratégia do Grupo 1, mas que os membros do grupo haviam discutido, sem formalizar um outro caminho, e que este caminho teria sido escolhido para compartilhar com toda a sala. Em razão da qualidade da imagem da produção da Figura 2, decidimos apresentar uma resolução detalhada e construída com base na estratégia e nos procedimentos utilizados por este grupo, Grupo 2. Ressalva-se que respeitamos a produção do Grupo 2, os equívocos na solução apresentada foram discutidos e retomados na discussão com todos os integrantes, guiados pelas formadoras.

Figura 2 - Produção escolhida pelo Grupo 2

Seja x: número total de pessoas; y: número de meninas; z: número de meninos. Assim,

$$
\begin{gathered}
x=y+z \Rightarrow x-15=(y-15)+2(y-15) \Rightarrow x=3 y-30 \\
x-60=5(z-45)+z-45 \Rightarrow x=5 z+z+60-45-225 \Rightarrow x=6 z-210 \\
3 y-30=y+z \Rightarrow z=2 y-30 ; \\
6 z-210=y+z \Rightarrow z=\frac{y}{5}+42 . \\
f_{1}: \mathbb{Z}_{+} \rightarrow \mathbb{Z}_{+}, \text {tal que } f_{1}(y)=2 y-30, f_{1}(y)=z ; \\
f_{2}: \mathbb{Z}_{+} \rightarrow \mathbb{Z}_{+}, \text {tal que } f_{2}(y)=\frac{y}{5}+42, f_{2}(y)=z .
\end{gathered}
$$

A abscissa do ponto de intersecção entre os gráficos que representam as funçôes $\mathrm{f}_{1}$ e $\mathrm{f}_{2}$ fornece a soluçấo do problema. 
continuação

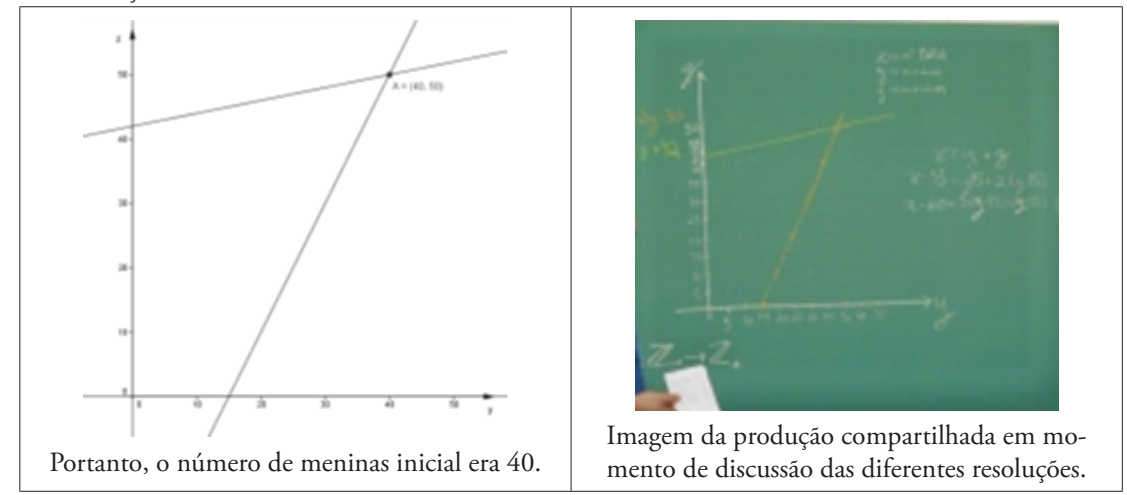

Fonte: Arquivo das autoras.

Na produção apresentada pelo Grupo 2 é possível reconhecer que foram utilizadas representaçôes algébricas e gráficas. Como estratégia de resolução eles utilizaram funçôes lineares e como procedimento de resolução, intersecção entre duas funçôes lineares. Apesar de os professores reconhecerem que o domínio dessas funçôes são números inteiros ao escrever $\mathrm{Z}$ $+=>Z+$ (domínio discreto), ao elaborarem suas representaçóes gráficas trabalharam com domínios contínuos. Após discussão com toda a sala, os professores reconheceram a necessidade de rever a elaboração destes gráficos, assim como a restrição dos números inteiros considerados, uma vez que assim como o elemento de saída do domínio é uma pessoa, o elemento de chegada também é, sendo necessário ser representado por um inteiro, reconhecendo que a função $\mathrm{f}_{1}$ tem o domínio $\{\mathrm{y} \varepsilon \mathrm{Z}+/ \mathrm{y} \geq 15\}$ e $\mathrm{f}_{2}$, $\{\mathrm{y} \varepsilon \mathrm{Z}+/ \mathrm{y}$ seja múltiplo de 5$\}$. O gráfico que representa a situação após a discussão é apresentado na Figura 3.

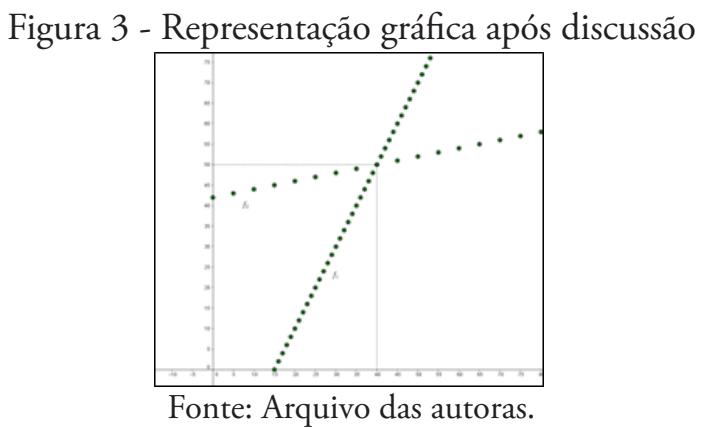


Também é possível reconhecer que foi utilizado o conceito de equações equivalentes no modo que os professores do Grupo 2 procederam. Esses professores tiveram a oportunidade de discutir o conceito de incógnita (valores desconhecidos de uma equaçáo) quando lidaram com a atividade por meio de equaçóes e o conceito de variável, ao representar a situação por meio de funçôes, e essa discussão foi abordada com todo o grupo de professores.

O Grupo 2, além de realizar tratamentos na representação algébrica, realizou uma conversão para a representação gráfica. É importante transitar entre os diferentes tipos de representação, fazendo a conversão. A atividade de conversão "conduz aos mecanismos subjacentes à compreensão" (DUVAL, 2003, p. 16). Na Figura 4 é apresentada a produção do Grupo 3.

Figura 4 - Produção escolhida pelo Grupo 3

\begin{tabular}{|c|c|c|c|c|}
\hline $\begin{array}{l}x z \text { inicial } \\
\text { de minision }\end{array}$ & $\begin{array}{l}\text { ne imicisel } \\
\text { de menimes }\end{array}$ & $\begin{array}{l}\text { dasit. } \\
\text { as as as }\end{array}$ & as $2 a \sin$ & 8 \\
\hline 501 & 70 & $50-15=35,2.35: 10$ & $5.25=118 \times 70-45=25$ & $\approx 35 \neq 125$ \\
\hline $\begin{array}{l}40 \\
60 \\
50\end{array}$ & $\begin{array}{l}50 \\
50 \\
40\end{array}$ & 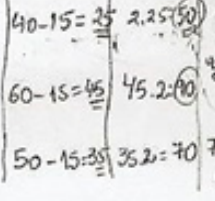 & 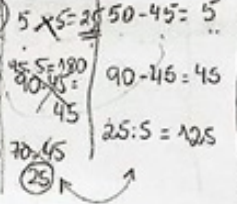 & $\begin{array}{l}\tilde{n} \quad 45 \neq 180 \\
\tilde{n} 25 \neq 125 .\end{array}$ \\
\hline
\end{tabular}

Fonte: Arquivo das autoras.

Na produção deste grupo é possível reconhecer uma estratégia por meio de operaçóes aritméticas que, a partir de um valor estipulado para o número de meninos e meninas, testou as condiçóes descritas no enunciado da questâo e, validou se os valores estipulados atendiam todas as condiçóes, uma vez que o número de meninas na $1^{\text {a }}$ situação devia ser de mesmo valor após a $2^{a}$ situação, permanecendo no mesmo sistema semiótico. Esse grupo de professores ao optar por realizar tratamentos nesse registro de representação "percebe, reconhece e se apropria de alguns aspectos do objeto" (D’AMORE; PINILLA; IORI, 2015, p. 112). Duval (2003) afirma que essa escolha está relacionada aos custos cognitivos que a representação necessita.

Além da discussão aritmética provocada, esse modo de representar a situação fez que esses professores retomassem a representação da situação 
por meio de funçóes, bem como discutissem que uma vez que o domínio e contradomínio são números de pessoas, são um conjunto finito. Vale fazer uma ressalva quanto aos modelos apresentados pelo Grupo 2, que não estão considerando a finitude dos conjuntos abordados na situaçáo.

Ao longo de todo o desenvolvimento da atividade é possível reconhecer a matemática interpretada como uma atividade humana, na qual cada professor em momento de formação foi envolvido como sujeito ativo, sujeito em que se reconhece responsável por seus processos de aprendizagem (princípio da atividade). Com esse envolvimento, os professores tiveram a oportunidade de compartilhar com seus grupos, assim como com toda a sala, suas estratégias e soluçôes, vivenciando a aprendizagem da matemática como uma atividade social (princípio da interatividade).

As atividades propostas, em especial a que aqui é apresentada, partiram de contextos que suscitavam alguma organização e são consideradas significativas, no sentido de ser familiar, exigir uma solução, refletir objetivos relevantes, de tal forma que ao lidar com elas desenvolva-se estratégias e procedimentos que abranjam tópicos do assunto da matemática em amplitude e profundidade (princípio da realidade). Elas favoreceram a utilização de vários conhecimentos e ferramentas matemáticas, podendo domínios da matemática serem tratados de forma integrada (princípio do entrelaçamento).

A possibilidade de lidar com a atividade por meio de diferentes representaçóes favoreceu a cada professor evidenciar sua compreensão e, com isso, a individualidade e os diferentes níveis de compreensão de matemática serviram para o desenvolver da aula (princípio de nível). Contudo, os envolvidos (todos professores) tiveram a oportunidade de refletir possibilidades acerca do processo e construir (mesmo que mentalmente) possibilidades de assumir uma prática pedagógica embasada em lidar com essas atividades e guiar seus alunos em seus processos de ensino e de aprendizagem (princípio da orientação).

\section{Consideraçóes finais}

O professor vivenciar episódios de formação, em que analisa suas próprias produçóes, configura-se uma oportunidade de reconhecer a análise da produção escrita, como fonte de informaçóes para a elaboração de trajetórias de ensino e aprendizagem. Ao lidar com uma atividade matemática e compartilhar as estratégias e procedimentos com os outros participantes, o 
professor pode refletir a respeito de como seus alunos poderiam lidar com determinada atividade, como poderiam expressar matematicamente suas ideias.

Com a proposta da atividade evidenciamos que, além da conversão da língua natural - escrita da atividade - para a linguagem matemática, tratamentos foram as atividades cognitivas escolhidas por dois dos grupos analisados, Grupo 1 e Grupo 3, que utilizaram representações algébricas e aritméticas, respectivamente. Já o Grupo 2, além de realizar tratamentos algébricos, realizou a conversão de representaçóes do registro algébrico para o gráfico.

Com as representaçôes que emergiram no desenvolvimento da atividade pelos grupos, inferimos que essas apresentam um caráter de variabilidade, pois mudam de acordo com os pontos de vista, experiências e conhecimentos dos envolvidos, bem como dos custos cognitivos de cada sistema semiótico escolhido.

Compartilhar as diferentes representaçôes em um curso de formação de professores permite que eles tenham contato com uma pluralidade de registros de representaçôes semióticas, que "favorece a construção cognitiva do objeto representado, uma vez que cada uma contribui de maneira específica com alguns aspectos do objeto" (D’AMORE; PINILLA; IORI, 2015, p. 112). Além disso, tal pluralidade "tem caráter complementar, sendo que, muitas vezes, as representaçóes diferenciadas de um mesmo objeto podem apresentar conteúdos diferentes, por isso há a necessidade de duas ou mais representaçôes, e a transição e coordenação entre as mesmas" (BUEHRING; FLORES; MORETTI, 2005, p. 26).

\section{Referências}

BARDIN, L. Análise de conteúdo. São Paulo: Edições 70, 2016.

BUEHRING, R. S.; FLORES, C. R.; MORETTI, M. T. O tratamento da informação nos livros didáticos e a teoria dos registros de representação semiótica. Revista Eletrônica de Republicação em Educação Matemática, Florianópolis, p. 24-32, 2005.

COBB, P.; YACKEL, E. Constructivist, emergent, and sociocultural perspectives in the context of developmental research. Educational Psychologist, Melbourne, v. 31, n. 3, p. 175-190, 1996. 
D’AMORE, B.; PINILLA, M. I. F.; IORI, M. Primeiroselementos de semiótica: sua presença e sua importância no processo de ensino-aprendizagem da matemática. São Paulo: Editora da Livraria da Física, 2015.

DUVAL, R.. Registros de representaçóes semióticas e funcionamento cognitivo da compreensão em Matemática. In: MACHADO, S. D. A. Aprendizagem em Matemática: registros de representaçâo semiótica. Campinas: Papirus, 2003. p. 11-34.

DUVAL, R. Semiosis y pensamiento humano: registros semióticos y aprendizajes intelectuales. Traduçáo de Myriam Vega Restrepo. Colômbia: Universidad del Valle, Instituto de Educación y Pedagogía, Grupo de Educación Matemática, 2004.

DRIJVERS, Paul. Learning algebra in a computer algebra environment. 2003. 174 f. Tese (Doutorado em Ensino de Ciências e Educação Matemática) Universidade de Utrecht, Utrecht, 2003.

FONT, V.; GODINO, J. D.; D’AMORE, B. Enfoque ontosemiótico de las representaciones em educación matemática. Granada: Universidade de Granada. 2005. Disponível em: <www.ugr.es -jgodinoindice_eos.htm>. Acesso em: 5 jun. 2006.

FREUDENTHAL, H. Geometry between the devil and the deep sea. Educational Studies in Mathematics. Ultrecht, v. 3, n. 3-4, p. 413-435, 1971.

FREUDENTHAL, H. Matemática nova ou educação nova? Perspectivas, Portugal, v. 9, n. 3, p. 317-328, 1979.

GRAVEMEIJER, K. How emergent models may foster the constitution of formal mathematics. Mathematical Thinking and Learning, Philadelphia, v. 1, n. 2, 1999, p. 155-177.

GRAVEMEIJER, K. RME theory and mathematics teacher education. In: SULLIVAN, P.; WOOD, T. (Ed.). International handbook of mathematics teacher education. Rotterdam: Sense Publisher, 2008. v. 1, p. 238-302.

HENRIQUES, A.; ALMOULOUD, S. Teoria dos registros de representação semiótica em pesquisas na educação matemática no ensino superior: uma análise de superfícies e funções de duas variáveis com intervenção do software Maple. Ciência e Educação, Bauru, v. 22, n. 2, p. 465-487, 2016. 
KEENE, K. A.; HALL, W.; DUCA, A. Sequence limits in calculus: using design research and building on intuition to support instruction. ZDM: The International Journal on Mathematics Education, Gewebestrasse, v. 46, n. 4, p. 561-574, 2014.

OTTE, Michael. Mathematical epistemology from a semiotic point of view. In: PME INTERNATIONAL CONFERENCE, 25., 2001, Utrecht. Proceedings... Utrecht: Utrecht University, 2001. p. 1-32.

SANTOS, E. R. dos. Análise da produção escrita em matemática: de estratégia de avaliação a estratégia de ensino. 2014. Tese (Doutorado em Ensino de Ciências e Educação Matemática) - Universidade Estadual de Londrina, Londrina. 2014.

SMITH, M. S.; HILLEN, A.; HEFFERNAN, C. Student-constructed representations: Vehicles for helping teachers understand students' mathematical thinking. In: BLUME, G.; HEID, M. K.; SMITH, M. S. 2001 Yearbook of the Pennsylvania council of teachers of mathematics: the role of representation in the teaching and learning of mathematics. State College, PA: The Council of Teachers of mathematics, 2001. p. 65-69.

SWINYARD, C. Reinventing the formal definition of limit: The case of Amy and Mike. Journal of Mathematical Behavior, New Jersey, v. 30, p. 93$114,2011$.

VAN DEN HEUVEL-PANHUIZEN, M. V. D. Assessment and Realistic Mathematics Education. Utrecht: CD-ß Press: Utrecht University, 1996.

VAN DEN HEUVEL-PANHUIZEN, M. V. D. Mathematics education in the Netherlands: a guided tour. Utrecht: Utrecht University, 2000. CDROM.

VAN DEN HEUVEL-PANHUIZEN, M. V. D. Reform under attack - Forty Years of Working on Better Mathematics Education thrown on the Scrapheap? No Way! In: THE ANNUAL CONFERENCE OF THE MATHEMATICS EDUCATION RESEARCH GROUP OF AUSTRALASIA, 2010, Fremantle. Proceedings... Fremantle: Merga, 2010. p. 3-7. 
356 Polyphonía, v. 28/2, jul.-dez. 2017

WATSON, A.; OHTANI, M. (Ed.). Task design in Mathematics Education. In: MARGOLINAS, C. et al. (Ed.). Proceedings of ICMI Study 22. Oxford: ICMI, 2013. p. 9-16.

Recebido em: 6 abr. 2017.

Aceito em: 17 jul. 2017. 